\title{
A CONTRIBUIÇÃO DOS JOGOS NAS PRÁTICAS EDUCATIVAS
}

\section{ALFABETIZADORAS}

Vaneide Corrêa Dornellas

ESEBA/UFU

vaneidedornellas@hotmail.com

Resumo: A busca de estratégias de ensino e ferramentas que promovam a construção do conhecimento pela criança deve ser fundamental para o professor alfabetizador. O aprendizado da leitura e escrita, bem como de cálculos e o desenvolvimento do raciocínio lógico não deve ser visto como atividade mecânica e repetitiva, sem a necessidade de reflexão pela criança. É importante que o aprendiz se aproprie, de modo consciente, de como funciona a língua e/ou a Matemática. Os jogos na alfabetização podem ajudar as crianças se tornarem mais autônomas na apropriação da escrita, do raciocínio e envolver ainda, conteúdos das Ciências, tanto sociais quanto da natureza. Jogando, a criança consegue, com mais facilidade comparar, criar, analisar, associar, nomear, calcular, classificar, compor, conceituar, e despertar o interesse pelos temas propostos. Os desafios, brincadeiras e prazer proporcionados pelos jogos podem levar as crianças a diferentes níveis de compreensão de forma lúdica, divertida e espontânea. Além de poder potencializar a criatividade e contribuir para o progresso intelectual das crianças, são recursos valiosos e motivadores do processo de aprendizagem e o desenvolvimento de habilidades.

Atualmente, muito tem se discutido sobre a importância da criança aprender divertindo-se. Os jogos como instrumento de aprendizagem tem sido objeto de estudo de educadores e pesquisadores e vem sendo, cada vez mais, usado como um recurso por muitos professores. Muitos profissionais que trabalham com crianças têm se interessado em buscar conhecimento sobre a temática, acreditando que assim, possam dar um melhor direcionamento ao seu trabalho pedagógico.

Os jogos e brincadeiras na sala de aula têm sido adotados por professores por acreditarem que, por meio deles, o indivíduo pode brincar naturalmente, testar hipóteses, explorar a sua espontaneidade criativa. Esses recursos não devem ser usados apenas para divertimento, mas sim, como meios que contribuem e enriquecem o desenvolvimento intelectual. Sua importância, portanto, está diretamente ligada ao 
desenvolvimento do ser humano em uma perspectiva social, afetiva, histórica, cultural e criativa.

As crianças precisam brincar, criar e inventar, pois, assim, podem melhor desenvolver o seu raciocínio e conduzir o seu conhecimento de forma mais descontraída e espontânea. Jogando, a criança consegue, com mais facilidade comparar, criar, analisar, associar, nomear, calcular, classificar, compor, conceituar, e despertar o interesse por temas propostos. Dessa forma, o jogo se torna uma oportunidade de avanço, porque jogando a criança experimenta, inventa, descobre, e tem a oportunidade de aprender e desenvolver suas habilidades. Além disso, sua inteligência e sua sensibilidade poderão ser ampliadas. As oportunidades que são oferecidas às crianças por meio de jogos garantem que ela possa melhor interagir com o próximo, respeitar regras, desenvolver a imaginação e cooperação. Bem como, aprender de forma mais simples e natural a resolver problemas, pensar, criar e desenvolver o senso crítico. Jogando, as crianças podem colocar desafios e questões para serem por elas mesmas resolvidas, dando margem para que criem hipóteses de soluções para os problemas colocados. O caráter social do jogo possibilita ao participante expor uma ideia e/ou analisar o ponto de vista de outros colegas, permitindo refletir sobre uma melhor jogada para o grupo ou sobre a jogada do adversário. Essa atitude pode levar a criança a compreender a importância de aceitar a opinião do outro, contribuindo para uma melhor interação social.

Desde bem cedo as crianças são capazes de brincar, inventar suas próprias brincadeiras e jogos. Segundo Kishimoto (2007), os jogos estão vinculados ao pensamento de cada criança, mesmo que ainda não os conheça, porque ela cria suas próprias fantasias por meio de brinquedos ligados ao seu cotidiano familiar ou às pessoas de sua família. À medida em que as crianças vão crescendo e se desenvolvendo emocional e cognitivamente, elas começam a colocar outras pessoas em suas brincadeiras, e é percebendo a presença do outro que começam a ser respeitados os limites e as regras. Quando uma criança se mostra capaz de seguir uma regra, percebe-se que seu relacionamento com outras crianças e também com adultos melhora, corroborando com a ideia de que os jogos influenciam no processo social e de aprendizagem das crianças. 
Dessa maneira, pode-se dizer que o jogo é importante no contexto escolar, não apenas para incentivar a imaginação nas crianças, mas também para auxiliar no desenvolvimento de habilidades sociais e cognitivas. Se torna, assim, importante ferramenta para o professor usar como recurso facilitador na compreensão dos diferentes conteúdos pedagógicos, inclusive, para alunos que apresentam dificuldades de aprendizagem. O trabalho com jogos matemáticos, por exemplo, pode transformar as atividades que, às vezes, são geradoras de sofrimento para muitos educandos em fonte de satisfação, motivação e interação social.

No contexto escolar, os jogos também propiciam uma melhor relação entre parceiros e grupos e por isso contribuem e enriquecem para o desenvolvimento social da criança. Para Kammi (1992, p.172) os jogos "envolvem regras e interação social, e a possibilidade de fazer regras e tomar decisões juntos é essencial para o desenvolvimento da autonomia". Na relação com o outro, é possível observar o comportamento das crianças para construir estratégias para a vitória, como também as relações diante da derrota. Isso é um importante aspecto que deve ser considerado pelo professor nas relações sociais dentro da sala de aula. É importante que o aluno desenvolva competências para a convivência com as pessoas, como, a capacidade em resolver divergências e conflitos, o auto-controle, aceitação de críticas, entre outros. Esses aspectos podem ser desenvolvidos por meio de jogos em sala de aula, se forem conduzidos devidamente, principalmente no início da vida escolar.

Por outro lado, a competição pode desviar a atenção do objetivo envolvido no jogo e isso pode se tornar um aspecto negativo. Por isso, ao propor os jogos em grupo, o professor deve enfatizar que o objetivo é levar os alunos a atingirem habilidades e conhecimentos. Uma das maneiras de amenizar esse problema é a adoção de jogos cooperativos e colaborativos, ao invés competitivos, na qual, um precisa ajudar o outro a resolver a questão proposta pelo jogo. É de grande importância os jogos cooperativos e em grupo, para desenvolverem desde pequenos o valor do trabalho coletivo, em que é preciso a ajuda e participação de todos. Em relação à competição nos jogos, precisa ser abordada de maneira delicada, para não criar rivalidades, porém, as crianças precisam aprender a perder e se posicionar corretamente diante da vitória ou derrota. E isso precisa ser introduzido desde a infância, pois é algo comum ao longo da vida. 
Trabalhar com os jogos nos anos iniciais, segundo Montessori (1965), é usar uma técnica que, sem dúvidas, facilita o desenvolvimento dos alunos. Assim, o professor poderá utilizar jogos e brincadeiras como recursos pedagógicos na construção da leitura e da escrita, bem como para o desenvolvimento do raciocínio lógico-matemático. Pode ser usado tanto para agilizar o raciocínio verbal, numérico, visual, a resolução de problemas, como para aprofundar e/ou consolidar os conteúdo das ciências naturais e sociais, enfim, para ensinar todos os conteúdos, bastando saber usá-lo na hora certa e da maneira correta.

Alguns professores têm dúvida quanto ao uso de material pedagógico, se tais experiências são exemplos de jogo ou apenas uso de material concreto. Muitos materiais são comumente utilizados em sala de aula, como material dourado, blocos lógicos, ábacos, sólidos geométricos, quadros de frações equivalentes, palitinhos de picolé, quadro posicional, réguas de cruisenaire e muitos outros. Por vezes, educadores questionam se esses materiais são considerados jogos. Kishimoto (1994), afirma que o uso de material concreto como subsídio à tarefa docente tem levado os educadores a se utilizarem de múltiplos objetos como suportes para momento lúdicos. Segundo a autora, se os objetos servem como auxiliar da ação docente e buscam-se resultados em relação a aprendizagem de conceitos e noções, ou mesmo, ao desenvolvimento de algumas habilidades, deve ser considerado um material pedagógico. De acordo com Kishimoto (1994, p.22),

ao permitir a manifestação do imaginário da criança, por meio de objetos simbólicos dispostos intencionalmente, a função pedagógica subsidia o desenvolvimento integral da criança. Neste sentido, qualquer jogo ou material empregado na escola, desde que respeite a natureza do ato lúdico, apresenta caráter educativo e pode receber também a denominação geral de jogo educativo.

Nesse sentido, o material pedagógico pode ser enquadrado nessas características como forma lúdica de lidar com um conceito. Para melhor compreensão das contribuições dos jogos e brincadeiras na aprendizagem, se faz necessário definir os conceitos de cada um, ou mesmo, da transição da brincadeira sem regras fixas ou previamente estabelecidas - para o jogo - com regras estabelecidas, que devem ser respeitadas, lembrando que essas regras podem ser flexíveis, se os participantes estiverem de acordo. Para fazer a distinção entre jogo e 
brincadeira pode-se dizer que o jogo é a atividade com regras que, na maioria das vezes, definem uma disputa, enquanto brincadeira é o ato ou efeito de brincar, ou seja, entreter-se, distrair-se com um brinquedo ou jogo. Mas, deve ser levado em consideração que, às vezes, a brincadeira não precisa de um material, basta apenas o corpo para brincar. Ao tentar estabelecer a diferença entre jogos e brincadeiras é possível considerar uma pequena variante: o jogo pode ser considerado uma brincadeira com regras e a brincadeira, um jogo sem regras. $O$ jogo se origina do brincar ao mesmo tempo pode ser o próprio brincar. Mas, isso não quer dizer que, durante essa brincadeira, ela vire um jogo, pois os participantes podem decidir criar regras. Um exemplo disso é quando uma criança corre atrás de outra no pátio da escola e outras crianças resolvem entrar na brincadeira e logo em seguida definem que estão brincando de pique-pega e colocam regras para a brincadeira.

Alguns jogos possuem regras específicas que não podem ser mudadas, como é o caso do jogo de xadrez, mas, em muitos casos, os jogos, mesmo com regras distintas, podem sofrer variações. Muitos desses jogos com regras os participantes ganham ou perdem. Os jogos com tabuleiros e cartas, por exemplo, possuem uma conotação mais competitiva, pois têm em sua definição que alguém sairá vencedor. Nesse sentido, propiciam a criança a lidar com a derrota e a perda.

Já uma brincadeira como brincar de casinha, apresenta um lado mais de integração, na qual visa entreter de forma lúdica, mas, permite ao professor a observância do comportamento e de detalhes importantes para entender, às vezes, um comportamento da criança, fora da brincadeira. São jogos com regras mais simples, mas que estimulam o desenvolvimento e a aprendizagem. Ao brincar de casinha, ou de outra situação como o médico no seu consultório, o professor com seus alunos, um policial que prende um ladrão, um bombeiro que socorre uma pessoa, uma repórter que faz uma entrevista, entre outras, a criança trabalha e desenvolve sua imaginação em situações criadas por ela. Segundo Gallahue (2008) a criança, por meio do jogo, trabalha o imaginário, joga como se tal coisa fosse o que não é, como se estivesse em um lugar onde não está, como se visse uma paisagem que não vê. As coisas no jogo não são o que são, mas, é como se fosse outra coisa. $E$ as outras crianças que entram no jogo podem ser o que elas não são, mas, é como se fossem outras crianças, incorporando personagens. A linguagem dessa brincadeira, que pode 
se tornar um jogo (por causa da criação, imposição ou concordância de regras), é a do modo condicional e imperativo: isto é uma casa, você vai ser a cozinheira, eu vou ser a mãe, ele vai ser o pai e, um pouco depois, todas aquelas coisas já o são, na sua imaginação, como se fosse realidade.

É importante o professor, enquanto mediador desse processo, conhecer os objetivos dos jogos e brincadeiras, para que o brincar não se torne brincar por brincar, mas, sim, uma situação a favor da aprendizagem, de acordo com a necessidade. Ao selecionar os jogos a serem utilizados no processo educativo, é importante considerar os conhecimentos das crianças. Na maioria das brincadeiras sem regras ou imaginárias, no jogo simbólico, por exemplo, a criança não percebe que o aprender esteja acontecendo, pois ela não vê intenção do professor, nesse sentido. Porém, em algumas situações, é preciso que o aluno compreenda o objetivo da brincadeira ou do jogo e encontre sentido, relacionando o conteúdo aplicado. Portanto, não adianta propor um jogo que esteja fora da realidade do aluno.

Nesse sentido, é interessante saber que brincadeiras simples, sem regras ou com regras que exigem raciocínio e estratégia, ajudam as crianças a compreenderem conceitos importantes em vários conteúdos, inclusive, matemáticos e linguísticos. Se torna, assim, importante saber aproveitar, ao máximo, o momento do jogo a favor da aprendizagem dos alunos, porque é um momento de manifestação de prazer e alegria. É um instante em que a criança se desenvolve a partir do que é inerente à sua faixa etária: o prazer em brincar. É por isso que jogos e brincadeiras se tornam tão importantes no processo de alfabetização.

Muitas vezes, professores alfabetizadores lançam mão do uso de jogos com seus alunos e recebem em troca conhecimentos consolidados sem se ater em processos mecânicos. Brincadeiras comuns, do convívio de crianças e professores se tornam fonte de regozijo e ao mesmo tempo de conhecimento.

Segue, alguns exemplos de jogos corriqueiros e simples que são usados em sala de aula e podem auxiliar na apropriação do código linguístico:

- Jogos para encadear sucessão de palavras que comecem com o som que terminou a anterior, ou com a mesma letra que começou a palavra anterior podem ajudar na compreensão da escrita das palavras e gerar motivação para compreensão do código linguístico; 
- Jogos de associação como a busca de palavras de uma profissão ou lugar onde se pode encontrar ou produto, relacionando-as entre si - ex: doce, doceiro, doceria;

- Jogo de inventar histórias em grupo desperta a imaginação e desenvolve a noção de início, meio e fim;

- Jogo de adivinhações, desperta o raciocínio e o pensamento;

- Brincadeira de telefone sem fio trabalha a concentração;

- Brincadeiras de imitar animais ou gestos - como na brincadeira ""o rei mandou" - trabalha a concentração

- Jogos de agilidade articulatória, palavras que comecem com um determinado som, jogos fonéticos - como os trava-línguas melhora a articulação entre as palavras e sílabas e a concentração;

- Jogos morfossintáticos que permitem conhecer, memorizar e sistematizar estruturas sintáticas, como os versinhos, músicas, histórias cumulativas ou seriadas, entre outros;

- Jogos semânticos em atividades como, as adivinhações ou charadas com estruturas rimadas e que escondem o nome de algo e é preciso averiguar do que se trata às vezes trazem pistas na própria charada bem como as piadas simples;

- Entre vários outros.

Ao realizar este tipo de jogos e brincadeiras, o professor estará desenvolvendo a aprendizagem linguística em seus alunos que serão pré-requisitos para o desenvolvimento das capacidades leitoras e escritoras. Jogos e brincadeiras simples também podem ajudar na compreensão de conceitos e comportamentos, do corpo e do espaço, como por exemplo:

- Brincadeiras com o corpo em movimento auxiliam as crianças a compreender e a relacionar conceitos de perto, longe, atrás, mais perto, em cima, na frente.

- Algumas brincadeiras podem fazer a criança a ter uma dimensão de tempo (antes - depois), quantidade (pouco - muito), compreensão da sequência (início-fim); 
- Jogos corporais e as dinâmicas ajudam as crianças a se expressar melhor, desinibirem, a perder a timidez e ajudam na coordenação motora e nas relações pessoais

- Jogos espontâneos são importantes pra que o professor conheça o comportamento de seus alunos frente a situações-problemas colocados durante o brincar;

- Adivinhar mímicas desenvolve vários aspectos motores, de concentração e de raciocínio;

- Jogos de perguntas e respostas ajudam na rapidez de raciocínio, na lógica, na forma de pensar, e na memorização de determinado assunto.

- Jogos em que só é preciso uma folha e um lápis possuem grande importância no desenvolvimento, como exemplo o jogo da velha, forca e adedonha;

- Brincadeiras de roda, amarelinha, morto-vivo, pular corda, pique-pega;

- Entre vários outros.

Existem inúmeros tipos de jogos que podem ser utilizados no ensino de Matemática para ajudar no desenvolvimento do raciocínio lógico matemático, como o xadrez, a dama e o dominó, o bingo, o dado, caça palavra, uno, jogos de boliche com garrafas pet para trabalhar as operações matemáticas, quebra cabeça, jogo da memória, entre outros. Esses tipos de jogos, quando convenientemente planejado, pode ser um recurso pedagógico eficaz para a construção do conhecimento matemático. Em relação ao desenvolvimento do pensamento matemático, existem diferentes tipos e aplicabilidade, que são aqui, divididos essencialmente em quatro:

- Jogos de construção são os que trazem aos alunos um assunto desconhecido. Ao jogar, sentem a necessidade de buscar novos conhecimentos para resolver as questões propostas. Dessa forma, permitem a construção do aprendizado, despertando a curiosidade a respeito de um tema.

- Jogos de treinamento são aqueles que permitem exercitar, colocar em prática, estender, o conhecimento já adquirido, aumentando assim, a autoconfiança e familiarização com o mesmo. Por meio desse tipo de jogo, muitas vezes, as crianças encontram novos caminhos para a resolução de um problema. São muito utilizados quando o professor percebe que alguns alunos 
precisam de reforço num determinado assunto. Nesse tipo de jogo, o fator sorte interfere na vitória.

- Jogos de aprofundamento são mais utilizados depois de já ter sido trabalhados um assunto ou tema. A partir do conhecimento já adquirido, o jogo exige sua aplicação.

- Jogos estratégicos: São jogos onde são trabalhadas as habilidades que compõem o raciocínio lógico. Os alunos buscam caminhos para atingirem o objetivo final, utilizando estratégias para isso. É preciso criar hipóteses, podendo pensar várias alternativas para resolver um determinado problema. $\mathrm{O}$ fator sorte não interfere no resultado. Exemplos: Dama, Xadrez, Freecell, Batalha Naval, Campo Minado.

Muitas vezes, docente utilizam alguns desses jogos, sem saber, ao certo seu objetivo, mas, saber sobre o escopo de sua aplicação se torna imprescindível para o sucesso do processo de uma aprendizagem significativa.

Para que o jogo devolva ao professor resultados satisfatórios é necessário que seja interessante e desafiador para as crianças resolverem. É necessário verificar se o jogo é propício à idade das crianças e está de acordo com o seu desenvolvimento. Pois, se a criança não entender o que está sendo realizado, dificilmente conseguirá aproveitar os benefícios do mesmo. Também é importante que o professor dê oportunidade para que todos possam participar ativamente do princípio ao fim do jogo. Enquanto mediador, é necessário acompanhar o comportamento das crianças no coletivo, mas também no âmbito individual. Pois, o momento do jogo, é sem dúvida, uma oportunidade do mediador conhecer as características individuais dos participantes.

Segundo Samulski (2006) o jogo é um bom caminho para mostrar a personalidade das pessoas. O pai poderá conhecer melhor a personalidade de seu filho e o professor, a do seu aluno. Basta deixá-los jogar e, respeitar o seu jogo, observando o seu comportamento. Há de se considerar que se a criança prefere os jogos de composição ou os que se desmancham, pode-se deduzir que ela tenha uma tendência à construção ou conquista. Se preferir os de invenção ou os de análise, pode-se deduzir uma tendência para a vida ativa e criativa. E se preferir os jogos sossegados ou os violentos pode-se deduzir a tendência para a vida contemplativa ou 
ativa. Se prefere jogar com ordem ou desordenadamente, se é constante nos seus jogos ou se os varia a cada momento, se prefere jogar acompanhado ou quer jogar sozinho, se jogando oferece a vitória ou a retém se manda ou obedece. Por meio do jogo pode-se perceber a personalidade e o comportamento no convívio social.

Outro aspecto importante que precisa ser considerado no jogo é a auto avaliação do aluno. O professor deve separar um momento ao final do jogo para que conversem sobre como foi o jogo, como se sentiram diante das situações; como sentiram a vitória ou derrota, se houver; da cooperação do colega, se houver; dependendo da proposta inicial.

Concluímos que por meio dos jogos as crianças desenvolvam um melhor relacionamento com outras crianças e com adultos, podem interagir melhor com o meio em que estão inseridas Ihes proporcionando um autoconhecimento. O jogo facilita a aprendizagem de conteúdos e habilidades a serem adquiridos pelas crianças em fase de alfabetização, de forma prazerosa e alegre. Além de melhorar a concentração dos alunos. A vida das crianças é voltada para situações lúdicas e todos os dias precisam de brincar e precisam de jogos com outras pessoas e crianças para o seu desenvolvimento tanto psíquico como motor.

É notório como jogos e as brincadeiras contribuem de forma muito benéfica para que as crianças em processo de alfabetização aprendam de uma forma mais rápida e de maneira concreta e divertida. Os alunos também ficaram mais motivados e interessados a aprender, buscar e aprimorar seus conhecimentos, no intuito de vencer, ser melhor aceito ou mesmo, de brincar.

Dessa forma, é uma interessante ferramenta para uso dos professores, lembrando que, requer estudo e conhecimento para que sejam usados adequadamente, em momentos estratégicos para que não se torne um jogo com fim em si mesmo. É importante também que saiba que tipo de jogos e assuntos/temas encaixam melhor com as possibilidades de trabalho dentro do conteúdo proposto.

O aprender ludicamente, se divertindo, é motivador para a criança e pode se tornar mais leve para o professor que deseja que seus alunos consolidem determinadas aprendizagens de forma natural na infância. 


\section{REFERENCIAS BIBLIOGRÁFICAS}

GALLAHUE, David L. Compreendendo o desenvolvimento motor de bebês,crianças, adolescentes e adultos. São Paulo- SP - Brasil, Ed. Phorte, 2005

KAMII, Constance; DECLARK, Geórgia. Reinventando a aritmética: implicações da teoria de Piaget. São Paulo: Papirus, 1992

KISHIMOTO, Tizuko Morchida. O jogo e a educação infantil. São Paulo: Pioneira, 1994

KISHIMOTO, TizukoMorchida. Jogos infantis: o jogo, a criança e a educação. 14. e.d. Petrópolis, RJ, 2007.

MONTESSORI, Maria. Pedagogia Científica: a descoberta da criança. São Paulo, Flamboyant, 1965.

SAMULSKI, D. Análise do conceito de saúde e dos fatores motivacionais para a prática de atividades físicas: estudo comparativo entre alunos do ensino básico. Revista Mineira de Educação Física, Viçosa, v.14, n.1, p.66-88, 2006. 